\title{
Incidental Testicular Pathologies in Patients With Idiopathic Hydrocele Testis: Is Preoperative Scrotal Ultrasound Justified?
}

\author{
MONA KAFKA ${ }^{1}$, KILIAN STROHHACKER ${ }^{1}$, FRIEDRICH AIGNER ${ }^{2}$, FABIAN STEINKOHL ${ }^{2}$, \\ WOLFGANG HORNINGER ${ }^{1}$, RENATE PICHLER ${ }^{1 *}$ and ISABEL HEIDEGGER ${ }^{1 *}$ \\ ${ }^{1}$ Department of Urology, Medical University Innsbruck, Innsbruck, Austria; \\ ${ }^{2}$ Department of Radiology, Medical University Innsbruck, Innsbruck, Austria
}

\begin{abstract}
Background/Aim: Hydrocele testis is a common disease with a prevalence of $1 \%$ in adults. Although it can be diagnosed by physical examination, scrotal ultrasound represents a standard diagnostic tool, to exclude underlying pathologies among them testicular or scrotal malignancies. Patients and Methods: We conducted a retrospective analysis of 156 patients aged between 20 and 60 years who underwent surgical hydrocelectomy between 2003 and 2018. Pre-surgical ultrasound, histological results, complications and patients' characteristics were analysed. Results: Malignancies were found in 0\% of patients in the presurgical ultrasound. Interestingly, we found a higher incidence of hydrocele testis in patients with increasing age and $27 \%$ presented with symptoms other than painless enlargement of the scrotum. Among them recurrent pain was the most common. Surgical complications occurred in only $3.2 \%$. Conclusion: Testicular cancer is an important differential diagnosis of hydrocele testis. However, in our study no case of incidental testicular cancer or scrotal malignancy was found in the pre-surgical ultrasound.
\end{abstract}

Hydrocele testis is a common urological disease with a reported prevalence of $6 \%$ in new-borns and $1 \%$ in adults (1). Generally, it is characterized by an increased amount of serous liquid in the cavitas serosa scroti (2). Although the exact pathogenic mechanisms of hydroceles in adults are not fully understood yet, an imbalance between absorption and

*These Authors contributed equally to this work.

Correspondence to: Isabel Heidegger, MD, Ph.D., FEBU, Associate Professor of Urology, Department of Urology, Medical University of Innsbruck, Anichstreet, 6020 Innsbruck, Austria. Tel: +43 51250424875, e-mail: isabel-maria.heidegger@i-med.ac.at

Key Words: Testicular cancer, hydrocele testis, ultrasound, scrotal malignancies. secretion of serous liquid in the cavitas serosa scroti seems to play a role. As summarized by Dagur et al. in 2016, hydroceles can be classified in many different types such as primary, secondary communicating and non-communicating, and inflammation- or trauma-induced hydroceles (3). Furthermore, all these subtypes seem to be associated with different aetiologies. Among them the most common is disruption of the lymphatic system. This is mostly observed after surgeries such as laparoscopic varicocelectomy (3).

Although the guidelines give no clear recommendation, scrotal ultrasound is performed in adult men with hydrocele as part of the diagnostic work-up $(4,5)$. This is mainly based on the fact that different pathologies like trauma, infection, testicular torsion or even testicular or scrotal tumors can be associated with the development of hydrocele testis $(6,7)$.

Generally, testicular cancer represents the most frequent tumor in young men $(8,9)$. According to the literature testicular/paratesticular cancer can have hydrocele testis as attendant symptom (10). Specifically, malignant mesothelioma of the tunica vaginalis, sarcomas, and other rare testicular/ paratesticular neoplasms are commonly associated with hydrocele testis (11-14). However, there exist no congruent literature data on how often a testicular cancer is found in patients with hydrocele testis as a primary symptom.

Therefore, the aim of this retrospective observational study was 1) to identify incidental testicular cancer or other testicular or scrotal pathologies in pre-surgical sonographic examination in patients with idiopathic hydrocele testis and 2) to determine possible biomarkers to identify those patients who might benefit from a pre-operative testicular sonography.

\section{Patients and Methods}

An ethical approval of the local ethic committee (1005/2018) was obtained for this retrospective observational trial. A total of 156 male patients aged between 20 and 60 years who underwent surgical removal of the hydrocele testis between January 2003 and January 2018 at our University Hospital were included. Patients with a 
Table I. Age distribution of men with hydrocele testis.

\begin{tabular}{lll}
\hline Age (years) & $\mathrm{n}$ & $\%$ \\
\hline $20-30$ & 28 & 18 \\
$31-40$ & 32 & 20 \\
$41-50$ & 43 & 28 \\
$51-60$ & 53 & 34 \\
\hline
\end{tabular}

Table II. Patients symptoms leading to surgery.

\begin{tabular}{lccc}
\hline Symptoms & $\mathrm{n}$ & $\begin{array}{c}\text { \% of symptomatic } \\
\text { patients }\end{array}$ & $\begin{array}{c}\text { \% of all } \\
\text { patients }\end{array}$ \\
\hline Pain episodes & 28 & 65.1 & 17.9 \\
Progressive size & 10 & 23.3 & 6.4 \\
Relapse & 3 & 6.9 & 1.9 \\
Acute scrotal pain & 2 & 4.7 & 1.3 \\
\hline Total & 43 & 100 & 27.6 \\
\hline
\end{tabular}

history of testicular cancer or other testicular diseases (e.g. epididymitis, spermatocele, scrotal trauma, torsion) were excluded from analyses. Statistical analysis was performed using Microsoft Office Excel 2016 (Microsoft Corp., Redmond, WA, USA).

\section{Results}

Demographic data. Mean age of patients included in the study was 43 (median 45, range $=20-60$ years). Age distribution is demonstrated in Table I.

In all patients a testicular ultrasound was performed the day before surgery by a designated uro-radiologist (F.A or F.S). The precise volume of the hydrocele was measured in $113(72.4 \%)$ patients while the volume of the testicles was documented in $27(17.3 \%)$ of patients. Mean volume of the hydrocele testis was $297 \mathrm{ml}$, with volumes ranging from 8 to $3500 \mathrm{ml}$. The mean testicular volume was $16.3 \mathrm{ml}$ in a range from $5.5 \mathrm{ml}$ to $34 \mathrm{ml}$.

One patient underwent a previous orchidopexy and one patient had a persisting hydrocele testis since childhood. Although these patients were excluded from our further detailed analysis, it is an interesting observation that 22 $(11.7 \%)$ of all patients with hydrocele testis had previous varicocelectomy.

Patients' symptoms. Although hydrocele testis is often described in the literature as painless swelling of the scrotum (15), $43(27.5 \%)$ of the patients in the present study were symptomatic. Among them a painful scrotum and a cosmetically disruptive increase in size were the most common reported symptoms (Table II). Interestingly, no
Table III. Surgical techniques applied.

\begin{tabular}{lrr}
\hline Surgical technique & $\mathrm{n}$ & $\%$ \\
\hline Van Bergmann & 132 & 84.6 \\
Winkelmann & 23 & 14.7 \\
Lord & 1 & 0.6 \\
\hline
\end{tabular}

Table IV. Surgical complications graded according to Clavien-Dindo.

\begin{tabular}{lrcc}
\hline Complications & $\mathrm{n}$ & $\%$ of all patients & Grade \\
\hline Early end of anaesthesia & 1 & 0.6 & $\mathrm{I}$ \\
Postsurgical infection & 1 & 0.6 & $\mathrm{I}$ \\
Revision needed & 2 & 1.2 & $\mathrm{IIIb}$ \\
Lesion of the testicular vessels & 1 & 0.6 & $\mathrm{IIIb}$ \\
No complication & 151 & 96.8 & \\
\hline
\end{tabular}

correlation between size of hydrocele testis and pain episodes were observed.

Surgical findings. In our study centre three different surgical techniques were applied (van Bergmann, Winkelmann and Lord) depending on the anatomical and pathological intraoperative findings as well as on the surgeons' preference. Table III provides an overview about the used surgical techniques applied in patients included in the study. In $5 / 156(3,2 \%)$ patients' intra- or postoperative complications were described. Complications were graded according to Clavien-Dindo (16) as demonstrated in Table IV.

Pathological ultrasound findings. No testicular cancer or any other malignancy of the scrotum was found in pre-surgical ultrasound $(0 \%)$. Also, histological findings of the resected scrotal tissue confirmed no malignancy.

\section{Discussion}

Hydrocele testis is a frequent diagnosis and is mostly identified with testicular sonography. Although, clinical examination is crucial for primary diagnosis, scrotal ultrasound is nowadays mostly performed as a standard additional diagnostic procedure (3). Generally, this is based on the assumption that a differential diagnosis of idiopathic adult hydrocele testis are neoplasms of the testicles and scrotum and therefore should be discriminated. Even though testicular cancer accounts for only $1 \%$ of all newly diagnosed neoplasms in males, it is the most frequent tumor 
in young men and therefore represents a highly important differential diagnosis.

All patients in our study presented with classic symptoms of an idiopathic hydrocele testis and without any indication for testicular cancer like palpable painless mass or elevation of AFP, $\beta \mathrm{HCG}$ or LDH. Patients with a previous history of any testicular malignancy including status post inflammation processes were excluded.

Interestingly, we did not find an incidental testicular cancer in pre-surgical ultrasound in any of the 156 patients. Also, the histological examination of the hydrocele walls was without any suspicion of an underlying malignant process like $e . g$. mesothelioma. Our results therefore strengthen the findings of Okorie et al. where 102 patients with longstanding hydrocele testis were examined for further underlying pathologies using ultrasound and no further abnormality was found (17). In contrast, Shephard et al. have investigated symptoms of testicular cancer and found hydrocele testis in only 28/1398 $(2 \%)$ of patients with testicular cancer (18).

Based on the literature and on the findings of the present study, scrotal ultrasound in patients with typical symptoms of idiopathic hydrocele testis might not be necessary in all cases, but should still be performed when resources and man power allows. In addition, scrotal ultrasound is a quick and low prized medical examination. However, if diagnostic medical resources are restricted, ultrasound can be omitted in patients without further risk factors for malignancies. Another important issue is the patient himself, as the testicles are a region of shame for the majority of men and thus one should restrict examinations in this region respecting patients' privacy whenever possible.

As secondary finding, we could demonstrate a clear age distribution of the occurrence of hydrocele testis. Twice as much hydroceles occurred in the age group of 51-60 years, compared with patients between the ages of 20-30 years ( $34 \%$ vs. $18 \%$ ), yet without known correlation to an observed pathophysiological correlation. Another interesting point was that $27.6 \%$ of patients reported symptoms with recurrent painful episodes being the most common. Peri- and postoperative complications occurred in $3.2 \%$. This shows that the resection of hydrocele testis is a safe operation with low complication rates.

\section{Conclusion}

No incidental testicular or scrotal cancer was found in the ultrasound examination of patients who presented with typical clinical symptoms of a hydrocele testis in our population. Thus, performing an ultrasound in patients with hydroceles routinely prior to surgery does not seem to be justified when a detailed history of illness and good physical examination is performed. Nevertheless, testicular cancer is an important differential diagnosis of any painless enlargement of the scrotum and should therefore be clearly excluded especially in younger patients with hydrocele of acute onset.

\section{Conflicts of Interest}

The Authors declare that they have no competing interests regarding this study.

\section{Authors' Contributions}

I.H. and R.P designed and directed the study, furthermore they obtained the consent of the ethics committee and made substantial contributions to the development of this work K.S. performed the data collection and analysis, M.K. wrote the paper with essential input of all authors, I.H., R.P., F.A., F.S. and W.H. provided crucial input and feedback on the final manuscript.

\section{Acknowledgements}

This research did not receive any specific grant from funding agencies in the public, commercial, or not-for-profit sectors.

\section{References}

1 Aumüller G, Aust G, Doll A, Engele J, Kirsch J, Mense S, Wurzinger LJ, Wesker K, Voll M, Vanselow H, Baum K and Lackner C: 2. Auflage. In: Duale Reihe Anatomie vol. 2. Stuttgart: Thieme; 2010.

2 Rioja J, Sánchez-Margallo FM, Usón J and Rioja LA: Adult hydrocele and spermatocele. BJU Int 107(11): 1852-1864, 2011. PMID: 21592287. DOI: 10.1111/j.1464-410X.2011.10353.x

3 Dagur G, Gandhi J, Suh Y, Weissbart S, Sheynkin YR, Smith NL, Joshi G and Khan SA: Classifying hydroceles of the pelvis and groin: An overview of etiology, secondary complications, evaluation, and management. Curr Urol 10(1): 1-14, 2016. PMID: 28559772. DOI: 10.1159/000447145

4 Sandlow JI, Winfield HN and Goldstein M: Surgery of the scrotum and seminal vesicles. In: Wein AJ, Kavoussi LR, Novick AC, Partin AW, Peters CA (eds.). Campbell - Walsh Urology. 9th ed. Philadelphia: Saunders Elsevier; 2007.

5 Williams NS, Bulstrode CJ and Ronan O'Connell P: Bailey and Love's short practice of surgery. International students' edition. London: Edward Arnold (publishers) Ltd; 2008.

$6 \mathrm{Ku} \mathrm{JH}$, Kim ME, Lee NK and Park YH: The excisional, plication and internal drainage techniques: a comparison of the results for idiopathic hydrocele. BJU Int 87(1): 82-84, 2001. PMID: 11121997. DOI: 10.1046/j.1464-410x.2001.00022.x

7 Lundström K-J, Söderström L, Jernow H, Stattin P and Nordin P: Epidemiology of hydrocele and spermatocele; incidence, treatment and complications. Scand J Urol 53(2-3): 134-138, 2019. PMID: 30990342. DOI: 10.1080/21681805.2019.1600582

8 Baird DC, Meyers GJ and Hu JS: Testicular cancer: Diagnosis and treatment. Am Fam Physician 97(4): 261-268, 2018. PMID: 29671528.

9 Park JS, Kim J, Elghiaty A and Ham WS: Recent global trends in testicular cancer incidence and mortality. Medicine (Baltimore) 97(37): e12390, 2018. PMID: 30213007. DOI: 10.1097/MD.0000000000012390

10 Barthold $\mathrm{J}$ and Kass E: Abnormalities of the penis and scrotum. 4. Auflage (Clinical pediatric urology). London, Martin Dunitz, 2002. 
11 López López C, Nova Sánchez E, Fernández Puentes JC, Lloréns Martínez FJ, Ruiz Macía J and García López F: Hydrocele as the first manifestation of paratesticular rhabdomyosarcoma. Arch Esp Urol 43(3): 288-291, 1990. PMID: 2369161.

12 Lee JS, Choi YD and Choi C: Primary testicular osteosarcoma with hydrocele. Virchows Arch Int J Pathol 445(2): 210-213, 2004. PMID: 15232746. DOI: 10.1007/s00428-004-1073-6

13 Aggarwal P, Sidana A, Mustafa S and Rodriguez R: Preoperative diagnosis of malignant mesothelioma of the tunica vaginalis using Doppler ultrasound. Urology 75(2): 251-252, 2010. PMID: 19969334. DOI: 10.1016/j.urology.2009.07.1275

14 Suzuki K, Shioji Y, Morita T and Tokue A: Primary testicular plasmacytoma with hydrocele of the testis. Int J Urol Off J Jpn Urol Assoc 8(3): 139-140, 2001. PMID: 11260342. DOI: 10.1046/j.1442-2042.2001.00269.x

15 Simpson M and Sundaram V: Urologic conditions in infants and children: inguinal hernia, hydrocele, and cryptorchidism. FP Essent 488: 16-20, 2020. PMID: 31894951.
16 Dindo D, Demartines N and Clavien PA: Classification of surgical complications: a new proposal with evaluation in a cohort of 6336 patients and results of a survey. Ann Surg 240(2): 205-213, 2004. PMID: 15273542. DOI: 10.1097/01.sla.0000133083.54934.ae

17 Okorie CO, Pisters LL and Liu P: Longstanding hydrocele in adult Black Africans: Is preoperative scrotal ultrasound justified? Niger Med J J Niger Med Assoc 52(3): 173-176, 2011. PMID: 22083049. DOI: $10.4103 / 0300-1652.86130$

18 Shephard EA and Hamilton WT: Selection of men for investigation of possible testicular cancer in primary care: a large case-control study using electronic patient records. Br J Gen Pract J R Coll Gen Pract 68(673): e559-565, 2018. PMID: 29970393. DOI: 10.3399/bjgp18X697949

Received March 17, 2020

Revised March 25, 2020

Accepted March 26, 2020 